\title{
Decentralization and spatial distribution of regional economic activity: does equalization
}

matter?

Santiago Lago-Peñas ${ }^{* *}$

REDE and University of Vigo
Diego Martínez-López ${ }^{* * *}$

University Pablo Olavide in Seville

This version: $9^{\text {th }}$ October 2008

\begin{abstract}
This paper investigates the effect of fiscal equalization on the spatial distribution of public activities and, therefore, on regional disparities in per capita GVA. With this aim, we use a simple theoretical model which is tested using data for the Spanish regions over the period 1986-2006. Our results show that a decentralized scenario with full equalization implies less differences across regions in per capita GVA and a more important share of public spending (production) on it in poorest territories, in comparison with a case in which decentralization is not accompanied by full fiscal equalization.
\end{abstract}

KEYWORDS: Fiscal equalization, decentralization, regional cohesion, non-market service production.

JEL CODE: H73, R12.

\footnotetext{
** Departamento de Economía Aplicada, Facultad de Ciencias Empresariales y Turismo, Campus Universitario 32004 Ourense. Spain. Email: slagop@uvigo.es.

**** Corresponding author. Department of Economics, University Pablo Olavide. Ctra. Utrera, km. 1. 41013 Seville. Spain. Email: dmarlop1@upo.es.
} 


\section{INTRODUCTION}

Fiscal equalization is relevant to guarantee that decentralization does not involve an increase in regional disparities regarding the provision of public services by sub-national governments. In this sense, equalization is often interpreted as a policy tool implemented to promote social cohesion across regions. At a first sight, therefore, equalization systems pursue to achieve equity and redistribution objectives. However, some decentralized services, such as education or health care, are growth-enhancing ${ }^{1}$. As long as these types of public expenditures are often provided by regional and local governments, promoting equalization also involves consequences on economic growth and efficiency. In this sense, the usual clear-cut distinction between the aims of regional policy (often identified with infrastructure investment) and equalization may be softened.

All in all, decentralization also affects the distribution of public activities and, consequently, the economic activity as a whole. As non-market services are also computed in GVA, decentralization may have two different effects. First, it may involve a reduction in the concentration of public activities in the nation capital city, increasing public activities in the rest of regions. Second, in the presence of regional disparities in fiscal capacity, decentralization on the revenue side may involve that public activities become less important in poorer regions. In contrast to a centralized framework, regional government revenues are in relation to the size of their own tax bases, and disparities in public activities between rich and poor regions are likely to arise. Of course, things may be different if decentralization is combined with equalization grants.

This paper is focused on this second effect. In section 2, we develop a simple theoretical model to illustrate the effects of decentralization with and without equalization. In section 3 , the model is empirically tested using data for Spain over the period 1986-2006. There are at least two

\footnotetext{
${ }^{1}$ See, for instance, Currais y Rivera (1999) and Barro and Sala-i-Martin (1999).
} 
reasons why the Spanish case is particularly relevant. First, this country has experienced a strong devolution process since the early eighties. Second, its institutional framework consists of different solutions for fiscal equalization, which include a complete equalization scheme for the majority of Spanish regions but also the presence of a fully autonomous financing system for two regions, Pais Vasco and Navarra, without scope for equalization. Finally, section 4 concludes.

\section{THE THEORETICAL MODEL}

This section aims at providing a theoretical motivation of the idea sketched in the Introduction. We analyze the effect of decentralization on the spatial distribution of public activities and, therefore, on GVA. Particularly, we deal with two different scenarios: 1) a centralized country in which the government, taking care about the welfare of all the individuals living in the nation, chooses the levels of public spending and tax rates for each region; and 2) a decentralized country in which the regional governments decide on their own provision of public services and the taxes needed for it and, consequently, fiscal equalization does not exist. The first case can be also interpreted as that of a decentralized country where there exists a full equalization of regional budgets from the upper level of government. Under this alternative, with similar levels of public expenditure across regions, the autonomy of regions would be limited to choose its composition.

We adopt a simple general equilibrium model with national public goods and two regions differing in their labor productivity, familiar from Caminal (2000), and appropriately simplified to deal with the issue we focus on here. The model features a country with two asymmetric regions, indexed by $i, i=A, B$. Each region is populated by a representative household, whose utility function has the following form: 


$$
U^{i}=c^{i}-\frac{1}{2}\left(l^{i}\right)^{2}+2\left(g^{i}\right)^{0.5}
$$

where $c, l$ and $g$ denote private consumption, labor and public spending, respectively. Output in each region is produced by technology $y^{i}=\theta^{i} l^{i}$, where $y$ denotes the level of production and $\theta$ is an exogenous parameter reflecting the productivity level. This is the main point where both regions differ. Hereafter, we assume that $\theta^{A}>\theta^{B}$, that is, region $A$ is relatively richer than region $B$. Output can be used for $c$ and $g^{2}$.

The (central) government obtains revenue exclusively through a proportional labor income tax,. Denoting the tax rate in region $i$ by $\tau^{i}$, the total tax revenue of government in such a region is $T^{i}=\tau^{i} y^{i}$. The representative household maximizes (1) subject to the following budget constraint:

$$
c^{i}=\left(1-\tau^{i}\right) \theta^{i} l^{i}
$$

The solution of this optimization problem yields the labor supply of household $l^{i}=\left(1-\tau^{i}\right) \theta^{i}$, and, hence, the private consumption according to (2). Plugging these optimal solutions into the utility function (1), we obtain the indirect utility function:

$$
V^{i}=\frac{1}{2}\left(1-\tau^{i}\right)^{2}\left(\theta^{i}\right)^{2}+2\left(g^{i}\right)^{0.5}
$$

At this point we distinguish two cases. In the first one, the central government decides upon public spending and taxes of both regions; recall that this situation can be identified with that in which there exists full equalization. By contrast, in the second case, the regional governments are completely autonomous and choose their own fiscal menus.

\footnotetext{
${ }^{2}$ We assume closed economies. Obviously, things would be different if trade in goods across regions was allowed but our main results concerning public spending below would continue being the same.
} 
The first environment requires defining a social welfare function at national level. As central government is interested in maximizing the welfare of household in both regions, the objective function of policy makers can be defined as follows:

$$
W=W\left(V^{A}, V^{B}\right)=\sum \alpha^{i} V^{i}
$$

that is, as the weighted sum of representative agents' utilities. The point here is to determine the values of $\alpha^{\prime} s$, i. e. the relative weights of each region's welfare by defining the national public policy. In a sense, these parameters can be seen as the degree of aversion of the country to regional inequality; indeed, taking account that the region $A$ is richer than the $B\left(\theta^{A}>\theta^{B}\right)$ and setting a range for $\alpha^{i}$ of $[0,1]$, with $\sum \alpha^{i}=1$, a redistributive regional policy would be given by $\alpha^{A}<\alpha^{B}$. Alternatively, the parameter $\alpha^{i}$ can be defined as a measure of needs, in a way increasing with the extent of regional population ${ }^{3}$. In line with the purpose of this paper, we shall follow a neutral redistributive pattern ${ }^{4}$. Consequently, $\alpha^{A}=\alpha^{B}=0.5$.

Budget constraint of national government is given by:

$$
\sum_{i=A, B} g^{i} \leq \sum_{i=A, B} \tau^{i}\left(1-\tau^{i}\right)\left(\theta^{i}\right)^{2}
$$

The optimization problem of the national government consists of choosing tax rates $\tau^{i}$ and levels of public spending $g^{i}$ to maximize (4) subject to (5). Hence, the equilibrium solution is characterized by the following equations:

\footnotetext{
${ }^{3}$ The underlying assumption behind this interpretation implies congestion costs in the provision of public goods.

${ }^{4}$ This is a reasonable assumption. Indeed, regional redistribution in real world mainly uses public investment as policy tool, instead of public services which are those where we focus on.
} 


$$
\begin{aligned}
& \frac{1-\tau^{A}}{\left(1-2 \tau^{A}\right)\left(g^{A}\right)^{-0.5}}-1=0 \\
& \frac{1-\tau^{B}}{\left(1-2 \tau^{B}\right)\left(g^{B}\right)^{-0.5}}-1=0 \\
& \alpha^{A}\left(g^{B}\right)^{0.5}-\alpha^{B}\left(g^{A}\right)^{0.5}=0 \\
& \sum_{i=A, B} g^{i}-\sum_{i=A, B} \tau^{i}\left(1-\tau^{i}\right)\left(\theta^{i}\right)^{2}=0 .
\end{aligned}
$$

We have numerically solved the equation system (6)-(9) with values of $\theta^{A}=1$ and $\theta^{B}=0.8$, and the neutrally redistributive parametrization of $\alpha^{\prime} s .{ }^{5}$ The results are reported in panel a) of Table 1.

\section{[TABLE 1 ABOUT HERE]}

The centralized outcome implies the same combination of public spending and taxes in both regions. However, given the initial difference in productivity between territories, the region A enjoys more output and, consequently, more private consumption. As a result of this, the ratios of public production over total production and of public production over private production (this is not directly reported in the Table 1 but easily computable by dividing $g^{i}$ and $c^{i}$ ) are higher in the poorer region $\mathrm{B}$.

Things are different when there exists a fully decentralization with no equalization. Under this new environment, regions choose their own combination of public spending and taxes, and the central government plays no role. Each region $i$ maximizes the indirect utility function of representative household (3) facing the following state budget constraint:

$$
g^{i} \leq \tau^{i}\left(1-\tau^{i}\right)\left(\theta^{i}\right)^{2}
$$

Solving for the tax rates $\tau^{i}$ and the levels of public spending $g^{i}$, the equilibrium is given by the two-equation system

\footnotetext{
${ }^{5}$ Details and programs regarding this resolution are available upon request.
} 


\begin{tabular}{|l|l|}
\hline$\frac{1-\tau^{i}}{\left(1-2 \tau^{i}\right)\left(g^{i}\right)^{-0.5}}-1=0$ & (11) \\
$g^{i}-\tau^{i}\left(1-\tau^{i}\right)\left(\theta^{i}\right)^{2}=0$, & (12) \\
\hline
\end{tabular}

which has been numerically solved again for values of $\theta^{A}$ and $\theta^{B}$ equal to 1 and 0.8 , respectively. The results are shown in panel b) of Table 1.

The new situation is quite different to the previous one. In a decentralized framework without equalization, total output $\left(y^{i}\right)$ is higher in rich region and lower in poor region than when a centralized scenario was considered. Moreover, the poor region B sets higher taxes and provides less public services than the rich region A. This has a direct impact on the ratios discussed above. Indeed, the share of public production over total production is now higher in the rich region A (0.3442) when is compared to the case of unitary country of panel a) (0.2960). The opposite occurs for the case of poor region B: a smaller ratio is found when decentralization without equalization is considered (0.3795 vs 0.4625). Although not reported in the Table, something similar happens when the ratio of public production over private production is analyzed.

Therefore, Table 1 is revealing for the purpose of this paper. Under a neutrally redistributive pattern of national fiscal policy, the poorer region always shows a higher share of public spending over regional GVA. This fact remains when a decentralized framework without equalization is considered, but in this case it is worthy to note that differences between regions in both ratios are smaller.

\section{EMPIRICAL RESULTS}

In this section, theoretical results are tested using data from Spain over period 1986-2006. The Spanish case is very interesting because of at least two reasons. First, the devolution process 
started in the early eighties. Since then, Spain has evolved from a highly centralized unitary state to a (de facto) federal one. Regional governments are now responsible for more than one third of total public expenditure. The second reason is related to the coexistence of two different fiscal federal arrangements: the common regime, applied to 15 regions or Comunidades Autonomas, and a special regime (sistema foral) applied to the other two regions (Pais Vasco and Navarra $)^{6}$. Fiscal equalization is full among the first group, but extremely weak in the case of Pais Vasco and Navarra. Insofar as their fiscal capacity is significantly above the average, both regions simultaneously enjoy higher per capita regional public revenues and slightly lower tax rates than common regime regions (Zubiri, 2007).

According to our theoretical model, at the start of the decentralization process we expect that 1) the variable $g$ was not correlated with $y$, and 2) the variables $g / y$ and $y$ were negatively correlated. Both results should hold if expenditure decentralization is complemented by full equalization, as in the case of the common regime. On the contrary, results should be different in the case of Pais Vasco and Navarra. For a given $y$, decentralization would involve higher values for $g$ than under the common regime. Moreover, negative correlation between variables $g$ and $g / y$ will be lower. In what follows the variable $y$ is defined as per capita total Gross Value Added (GVA) and the variable $g$ is defined as the per capita value added corresponding to nonmarket services. Both variables have been standardized (mean=100). Data source is the Spanish National Institute of Statistics (www.ine.es) ${ }^{7}$.

In order to analyze changes over time, cross-section data for three time points (1986, 1996 and 2006) have been used. The starting year is not a choice but an imposition: regional data for production of non-market services are not available before 1986. Anyway, decentralization of public expenditure to regional governments in 1986 was still relatively low (13.6\% of total

\footnotetext{
${ }^{6}$ See Lago-Peñas (2005) for an overview on Spanish fiscal federalism.

${ }^{7}$ For the whole period the domestic service is included by the INE into the category non-market services. However, disaggregated data available for years 2000 to 2004 shows that the former represents less than $7 \%$ of the latter. Moreover, this share tends to be higher in richer regions. Therefore, if it has any effect on results, it would play against our hypothesis.
} 
public expenditure in Spain). On the contrary, decentralization of expenditure is very high in 2006 (35.8\% of total public expenditure), with year 1996 in a middle point $(22.6 \%)^{8}$. Finally, the ratio $g / y$ rose in Spain from 12.9\% in 1986 to $14.5 \%$ in 2006.

With the aim of checking the hypothesis, the following four equations are estimated:

\begin{tabular}{|c|c|}
\hline$g_{i t}=\alpha_{1}+\alpha_{2} \cdot D 96_{i t}+\alpha_{3} \cdot D 06_{i t}+\alpha_{4} \cdot y_{i t}+\alpha_{5} \cdot y_{i t} \cdot D 96_{i t}+\alpha_{6} \cdot y_{i t} \cdot D 06_{i t}+\varepsilon_{i t}$ & (13) \\
\hline$\frac{g_{i t}}{y_{i t}}=\beta_{1}+\beta_{2} \cdot D 96_{i t}+\beta_{3} \cdot D 06_{i t}+\beta_{4} \cdot y_{i t}+\beta_{5} \cdot y_{i t} \cdot D 96_{i t}+\beta_{6} \cdot y_{i t} \cdot D 06_{i t}+\mu_{i t}$ & (14) \\
\hline $\begin{array}{l}g_{i t}=\alpha_{1}+\alpha_{2} \cdot D 96_{i t}+\alpha_{3} \cdot D 06_{i t}+\alpha_{4} \cdot y_{i t}+\alpha_{5} \cdot y_{i t} \cdot D 96_{i t}+\alpha_{6} \cdot y_{i t} \cdot D 06_{i t}+\alpha_{7} \cdot D P V N A_{i}+ \\
+\alpha_{8} \cdot D 96_{i t} \cdot D P V N A_{i}+\alpha_{9} \cdot D 06_{i t} \cdot D P V N A_{i}+\varepsilon_{i t}\end{array}$ & (15) \\
\hline $\begin{array}{l}\frac{g_{i t}}{y_{i t}}=\beta_{1}+\beta_{2} \cdot D 96_{i t}+\beta_{3} \cdot D 06_{i t}+\beta_{4} \cdot y_{i t}+\beta_{5} \cdot y_{i t} \cdot D 96_{i t}+\beta_{6} \cdot y_{i t} \cdot D 06_{i t}+\beta_{7} \cdot D P V N A_{i}+ \\
+\beta_{8} \cdot D 96_{i t} \cdot D P V N A_{i}+\beta_{9} \cdot D 06_{i t} \cdot D P V N A_{i}+\mu_{i t}\end{array}$ & (16) \\
\hline
\end{tabular}

Variable DPVNA equals 1 for observations corresponding to Pais Vasco and Navarra, and 0 otherwise. Variable D96 equals 1 for observations corresponding to year 1996, and 0 otherwise. By the same token, variable D06 equals 1 for observations corresponding to year 2006, and 0 otherwise.

Equations (13) and (14) are estimated using data from common regime regions. Region of Madrid is excluded to avoid biases due to the "capital effect": country capitals in both central and federal countries tend to concentrate civil servants and public activities in a more intense proportion $^{9}$. Variables D96 and D06 allow to control for differences in parameters over time. For instance, the effect of $y$ on $g$ in 2006 is $\alpha_{4}+\alpha_{6}$ and the intercept in 2006 is $\alpha_{1}+\alpha_{3}$.

\footnotetext{
${ }^{8}$ Data source for 1986 and 1996 is DGCHT (2001). Data for 2006 come from IGAE (2007).

${ }^{9}$ Madrid ranked first in variable $g$ in both 1986 and 2006. However, the effect of decentralization is clear. Being 100 the per capita average, Madrid was 151 in 1986 but just 125 in 2006. On the contrary, Madrid improved in per capita GDP (variable y). In 1986, Madrid was fourth in the ranking (121 with average=100). In 2006 was the first (132). As a consequence, Madrid dropped from the $2^{\text {nd }}$ to the $11^{\text {th }}$ in terms of ratio $g / y$. In 1986 it was well above the average value of $g(16.0 \%$ versus an average of $12.9 \%)$. In 2006 it was below (13.7 \% versus $14.5 \%)$.
} 
In specifications (15) and (16) data from Pais Vasco and Navarra are used and several interactions with variable DPVNA are included to check the effect of decentralization on $g$ and $g / y$. For instance, controlling for differences in per capita GVA, the effect of low equalization on $g$ in 2006 is captured by $\alpha_{9}$.

In sum, the main hypothesis to be tested are the following:

1. In a centralized framework variable $g$ is not correlated with $y\left(\alpha_{4}=0\right)$.

2. In a centralized framework variables $g / y$ and $y$ are negatively correlated $\left(\beta_{4}<0\right)$.

3. In a decentralized framework with full equalization, previous results hold $\left(\alpha_{4}+\alpha_{6}=0, \quad \beta_{6}=0\right)$.

4. Decentralization without full equalization increases the value of $g$ and $g / y$ in richer regions $\left(\alpha, \alpha_{9}>0, \quad \beta_{8}, \beta_{9}>0\right)$.

\section{[TABLE 2 ABOUT HERE]}

Equations are estimated by OLS. A battery of tests were carried out to verify that econometric specifications are correct and OLS results are reliable ${ }^{10}$. Estimates of parameters $\alpha_{1}$ to $\alpha_{6}$ are the same in columns 1 and 3 of table 2 . The same applies to parameters $\beta_{1}$ to $\beta_{6}$ in columns 2 and 4. Moreover, parameters for interactions with variable D96 show in all cases the same sign than corresponding interactions with D06, but lower t-statistics: the higher the decentralization,

\footnotetext{
${ }^{10}$ White's test is a test of the null hypothesis of no heteroskedasticity against heteroskedasticity of unknown, general form. Ramsey's RESET test is a general test for the following types of specification errors: Omitted variables, incorrect functional form, correlation between the exogenous variables and the random term which may be caused, among other things, by measurement error or simultaneity. The Jarque-Bera statistic tests for the null hypothesis of normally distributed errors. Residuals in 2006 (1996) are uncorrelated with residuals in 1996 (1986) in any estimate.
} 
the stronger its effects. Parameters $\beta_{2}$ and $\beta_{3}$ reflect the increase of the ratio $g / y$ on average over time.

Econometric estimates soundly confirm hypothesis 1 and 2. Variable $g$ is not correlated with $y$ (t-statistics below unity) and variables $g / y$ and $y$ are negatively correlated (t-statistic over 4.40). Hypothesis 3 is also verified. Using a Wald test the hypothesis $\alpha_{4}+\alpha_{6}=0$ cannot be rejected (p-value $=0.65$ and 0.63 ). Parameter $\beta_{6}$ is negative and significant at $10 \%$. That means that contrary to expected, decentralization tended to strength the negative relationship between variables $g / y$ and $y$. Fiscal equalization is the responsible for this result. Finally (hypothesis 4), both parameters $\alpha_{9}$ and $\beta_{9}$ are positive and significant at $10 \%{ }^{11}$ : while Navarra and Pais Vasco did not enjoy higher levels of $g$ and $g / y$ in 1986 ( $\alpha_{7}=\beta_{7}=0$ ), they do in 2006. In other words, decentralization without equalization means regional divergence in per capita public activities and then in per capita GVA.

\section{CONCLUDING REMARKS}

The standard approach to equalization in decentralized countries uses to study the incentive effects created by the grants coming from the upper-level of government. On the other hand, the debates on public policies and regional disparities focus upon public investment as the main tool for achieving convergence across territories. In a sense, this paper is located between both issues as long as we have provided a theoretical motivation and empirical evidence about the links between equalization and the distribution of economic activity across regions.

Particularly, we have shown how the degree of equalization affects regional income and its composition. Regarding a centralized country (or the equivalent case: a decentralized nation

\footnotetext{
${ }^{11}$ Coefficients $\alpha_{8}$ and $\beta_{8}$ are also positive but just marginally significant (p-values $<0.20$ ): the relationship is stronger over time.
} 
with full equalization), the share of public production on total GVA is higher in poor regions and, consequently, its relevance by determining the regional income becomes more powerful. By contrast, when decentralization without equalization is considered, both the theoretical and empirical results confirm that public production not only reduces its share on total income, but also can be seen as a force driving to divergence in per capita GVA across regions.

At least two main policy implications can be derived from this paper. First, policy makers must be aware that equalization systems have consequences on the spatial distribution of GVA. This should not imply a complex design of intergovernmental grants for taking account this (new but obvious) effect but simply and literally "be aware of it”. Equalization systems are complicated enough to insert new constraints by defining and performing them. Second, consumption public expenditures, such as education and public health, reveal as powerful instruments in regional policies aimed at reducing spatial disparities. In a context in which the bulk of regional polices has been concentrated on transport infrastructures, it could be interesting to explore more intensively new ways of favoring convergence. For instance, advanced programs of human capital investment or public amenities encouraging the immigration of highly qualified workers (Lago-Peñas and Martínez-López, 2008). 
Acknowledgments: We thank the financial support from the Spanish Ministry of Science and Technology (Project No. SEC 2006-04803).

\section{REFERENCES}

Barro, R. J., Sala-i-Martin, X., 1999. Economic Growth. The MIT Press, Cambridge.

Caminal, R., 2000. Measuring regional fiscal transfer induced by national budgets. International Tax and Public Finance 7, 195--205.

Currais, L., Rivera, B., 1999. Income variation and health expenditure: Evidence for OECD countries. Review of Development Economics 3 (3), 258--267.

DGCHT 2001. La descentralización del gasto público en España. Período 1984-1998., Ministerio de Economía y Hacienda. Madrid.

IGAE 2007. Avance de la actuación presupuestaria de las Administraciones Públicas., Ministerio de Economía y Hacienda. Madrid

Lago-Peñas, S., 2005. 'Evolving federations and regional public deficits: Testing the bailout hypothesis in the Spanish case'. Environment and Planning C: Government and Policy, 23 (3), 437--454.

Lago-Peñas, S., Martínez-López, D., 2008. Convergence and public investiment: Regional policies revisited, in: Ulrike Stierle-Von Schuetz et al (Eds.): Regional economics: New challenges for theory, empirics and policy, Edward Elgar, Chentelham forthcoming.

Zubiri, I., 2007. Los sistemas forales: características, resultados y su posible generalización, in: Lago-Peñas, S. (Ed.): La financiación del Estado de las autonomías: Perspectivas de futuro, Instituto de Estudios Fiscales, Madrid, pp. 355--387. 
Table 1: Numerical resolution of optimization problem of government

\begin{tabular}{|l|c|c|c|c|}
\hline & \multicolumn{2}{|c|}{$\begin{array}{c}\text { Panel a } \\
\text { Unitary country } \\
\text { (Full equalization) }\end{array}$} & \multicolumn{2}{c|}{$\begin{array}{c}\text { Panel b } \\
\text { Decentralized country } \\
\text { (No equalization) }\end{array}$} \\
\hline Region & $A$ & $B$ & $A$ & $B$ \\
\hline$g^{i}$ & 0.1891 & 0.1891 & 0.2257 & 0.1507 \\
\hline$\tau^{i}$ & 0.3610 & 0.3610 & 0.3442 & 0.3795 \\
\hline$l^{i}$ & 0.6389 & 0.5111 & 0.6557 & 0.4963 \\
\hline$y^{i}$ & 0.6389 & 0.4089 & 0.6557 & 0.3970 \\
\hline$c^{i}$ & 0.4498 & 0.2198 & 0.4300 & 0.2463 \\
\hline$g^{i} / y^{i}$ & 0.2960 & 0.4625 & 0.3442 & 0.3795 \\
\hline
\end{tabular}

Note: The values of $\theta^{A}$ and $\theta^{B}$ are 1 and 0.8 , respectively.

Table 2: Econometric estimates of equations (13), (14), (15) and (16)

\begin{tabular}{|c|c|c|c|c|}
\hline Equation & $(13)$ & $(14)$ & $(15)$ & $(16)$ \\
\hline Dependent variable & $\boldsymbol{g}$ & $\boldsymbol{g} / \boldsymbol{y}$ & $\boldsymbol{g}$ & $\boldsymbol{g} / \boldsymbol{y}$ \\
\hline Intercept & $0.822^{* * *}$ & $0.242^{* * *}$ & $0.832^{* * *}$ & $0.243^{* * *}$ \\
& $(5.03)$ & $(9.46)$ & $(5.26)$ & $(9.86)$ \\
\hline $\boldsymbol{D 9 6}$ & 0.089 & $0.069^{*}$ & 0.074 & $0.067^{*}$ \\
& $(0.37)$ & $(1.83)$ & $(0.32)$ & $(1.84)$ \\
\hline $\boldsymbol{D 0 6}$ & 0.250 & $0.089^{* *}$ & 0.024 & $0.089^{* *}$ \\
& $(0.93)$ & $(2.11)$ & $(0.93)$ & $(2.18)$ \\
\hline $\boldsymbol{y}$ & 0.149 & $-0.113^{* * *}$ & 0.138 & $-0.114^{* * *}$ \\
& $(0.91)$ & $(4.41)$ & $(0.87)$ & $(4.62)$ \\
\hline $\boldsymbol{y} \cdot \boldsymbol{D 9 6}$ & -0.119 & -0.049 & -0.104 & -0.046 \\
& $(0.48)$ & $(1.25)$ & $(0.43)$ & $(1.25)$ \\
\hline $\boldsymbol{y} \cdot \boldsymbol{D 0 6}$ & -0.252 & $-0.076^{*}$ & -0.245 & $-0.076^{*}$ \\
& $(0.90)$ & $(1.73)$ & $(0.90)$ & $(1.79)$ \\
\hline $\boldsymbol{D P V N A}$ & & & 0.006 & 0.003 \\
& & & $(0.06)$ & $(0.21)$ \\
\hline DPVNA・D96 & & & 0.197 & 0.030 \\
& & & $(1.40)$ & $(1.35)$ \\
\hline DPVNA・D06 & 0.05 & 0.70 & $0.266 *$ & $0.044^{*}$ \\
& 42 & 42 & 0.29 & $(1.87)$ \\
\hline $\mathrm{R}^{2}$ & 0.37 & 0.60 & 48 & 0.68 \\
\hline Number of observations & 0.80 & 0.09 & 0.33 & 48 \\
\hline White (p-value) & 0.56 & 0.44 & 0.87 & 0.09 \\
\hline RESET (p-value) & 0.65 & & 0.67 & 0.09 \\
\hline Jarque-Bera (p-value) & & & 0.63 & 0.58 \\
\hline Wald test (p-value) & & & \\
\hline $\mathrm{H}_{0}: \alpha_{4}+\alpha_{6}=0$ & & & & \\
\hline
\end{tabular}

Notes: ${ }^{* * *} \mathrm{p}<0.01,{ }^{* *} \mathrm{p}<0.05,{ }^{*} \mathrm{p}<0.1$ Values corresponding to standard t-statistics are in parentheses. 